\title{
CLINICAL AND RADIOGRAPHIC STUDY TO EVALUATE MARGINAL BONE LEVEL AROUND ONE PIECE AND TWO PIECE OF IMMEDIATE LOADED IMPLANTS
}

\author{
Rifaie, Ahmed Osama ${ }^{1 *}$, Magdy Kamel Mohamed ${ }^{2}$, Mohamed Ismail Assadawy ${ }^{2}$
}

\begin{abstract}
Objective: The present study was done to evaluate the marginal bone level around immediate loaded implants using one piece and two piece implants. Subjects and methods: A group of 22 patients were divided into two groups; Group 1: 11 Patients received immediate loaded implant placement using one piece implants. Group 2: 11 Patients received immediate loaded implant placement using two piece implants. According to clinical evaluation; plaque index, gingival index and peri-implant probing depth were recorded and measured at three, six months and nine months; also implant quality score was measured. Radiographically, marginal bone level was measured and bone density and compared in three months, six months, nine months. Results: Group 1 showed a significant decrease in the peri-implant probing depth compared to Group 2. Group 1 showed significant buccal marginal bone loss than Group 2 over all the time intervals. There is no significant difference in the palatal or mesial or distal surface between the two groups. Also no significant difference between the two groups including plaque index or gingival index nor bone density. Concerning the implant quality scale; $100 \%$ of group 2 were scale 1 , while $50 \%$ of group 1 were considered scale 1. Conclusion: Immediate loading of two piece dental implants appeared significantly superior than one piece type.
\end{abstract}

KEY WORDS: Marginal bone level (MBL), crestal bone loss (CBL), probing depth (PD).

\section{INTRODUCTION}

It is well documented that, tooth extraction has been followed by a reduction of buccolingual as well as apico-coronal dimension of the alveolar ridge at the edentulous area ${ }^{(1,2)}$. Immediate loading of implants has been defined as a situation where the suprastructure is attached to the implants no later than $72 \mathrm{~h}$ after surgery. The main advantage in this approach is a combination of preservation of the alveolar bone by implant and preservation of the peri-implant mucosa by the immediate provisionalization ${ }^{(3,4)}$.
The original Branemark concept consists of a two piece dental implant designed to be used in a two stage treatment procedure. The implant is inserted into the bone after raising a soft tissue flap, which is subsequently repositioned to cover the implant during healing. Following a healing period, a new flap is raised, and a transmucosal abutment is attached to the implant to allow the prosthesis to be connected ${ }^{(5)}$.

One-piece implants were introduced to incorporate the transmucosal abutment as an integral part of

1. Masters Candidate, Oral Medicine Department, Faculty of Dental Medicine, Al-Azhar University, Boys, Cairo.

2. Associate Professor, Oral Medicine Department, Faculty of Dentistry, Al-Azhar University, Cairo

-Corresponding author: osos.faith@gmail.com 
the implant and thus eliminate the structural weakness built in two-piece implants. One piece implants offer many advantages like strong unibody design, no split parts, single-stage surgery with either flap or flapless approach, and simple restorative techniques. A one-piece implant is intended for immediate function as well as for immediate placement in fresh extraction sockets ${ }^{(5)}$.

It was concluded that the absence of implant/ abutment interface (microgap) at the bone crest in one-piece implants was associated with reduced peri-implant inflammatory cell accumulation and minimal bone loss ${ }^{(6)}$.

The long term preservation of crestal bone height around osseo-integrated implants is often used as a primary success criterion for different implant systems. The radiographic evaluation of bone forms a very important and viable means of detecting health and stability of bone around the peri-implant hard tissue. A decrease of marginal bone loss (MBL) indicates that the implant is loosening its bony anchorage $^{(7)}$

Immediate implant loading was found to have an effect on MBL. Immediate loading, within 48 hours, is found to have a significant effect on early MBL. This increase in MBL may be explained by load concentrated at the crestal bone caused by micromobility of early loaded non-integrated implants ${ }^{(8)}$.

It was felt that performing a study on measuring marginal bone level around immediate loaded dental implants using one piece and two piece implants may give us more data to increase the success of these implants. Additionally, it will be of interest to examine the efficacy of this procedure clinically and radiographically.

\section{SUBJECTS AND METHODS}

A group of 22 patients were selected from Outpatient Clinic, Department of Oral Medicine, Periodontology, Oral Diagnosis and Oral Radiology,
Faculty of Dental Medicine, (Boys, Cairo), AlAzhar University.

Patients were divided into two groups; The study group (Group 1): included 11 patients ranged in age (between $18-42$ years old with a mean age $34.3 \pm$ 4.6) received immediate loaded implant placement using one piece implants.

The control group (Group 2): included 11 patients ranged in age (between 30 -38 years old with a mean age $36 \pm 2$ ) received immediate loaded implant placement using two piece implants.

Eighteen patients were females and 4 were males. In one piece group, $77 \%$ of the implant were upper teeth and $33 \%$ in lower teeth, in comparison to $100 \%$ upper teeth in two piece group. All teeth were single rooted.

ROOTT (Neobiotech, Republic of Korea) implants were used in this study. Two piece type and one piece type were used. The two piece type having conical form with self-tapping thread and reliable tapered connection. While the one-piece implant with compressive self tapping threads and tapered form, also an adjustable abutment slope angle (up to $\left.15^{\circ}\right)$. We used cemented retained abutments.

In one piece group, $75 \%$ of the implants were 3.5 in width and $25 \%$ were 4 in width; in comparison to $50 \%$ in each size $(3.4 \& 4)$ in two pieces group. Concerning the length of the implants used; In one piece group, $25 \%$ of the implant were 10 in length, $25 \%$ were 12 and $50 \%$ were 14 , in comparison to $50 \%$ in each size $(14 \& 16)$ in two pieces group

Surgery was performed under local anaesthesia and strict aseptic conditions. All the surgeries were done flapless, atraumatic extraction was done using Periotome. After tooth extraction, the socket was cleaned and irrigated with normal saline and curettage was done by bone currette to remove granulation tissue in the socket. Sequential drilling with copious irrigation was carried out till the 
desired dimensions were achieved depending on the selected implant. If the gap between the bone and the implant was more than two $\mathrm{mm}$; xenograft bone (ONE, Neo biotech) was placed in this area, we needed bone graft in just two cases; one in each group, then Provisional restoration (free from occlusion) was placed at time of surgery or within 48 hrs. The final prosthesis was placed after four months from surgery.

Patients were evaluated clinically at 3, 6, 9 months postoperatively and CBCT were recorded at baseline, 3, 6, and 9 months postoperatively.

CBCT scan was done on Planmeca Promax 3D Mid Proface (Helsinky, Finland). CBCT scanner with following values $90 \mathrm{Kv}, 12.5 \mathrm{~mA}$, voxel size 200 micron, FOV $8 \mathrm{~cm} 8 \mathrm{~cm}$. All data was imported to Planmeca Romexis 5.3.1 R software.

The significance level was set at $(p \leq 0.05)$. The data were collected, computed, tabulated and statistically analysed by independent $t$ test (for comparison between the two groups) and ANOVA t test with Tukey's post hoc test (for comparison between subsequent readings within the same group) using statistical package of scientific studies (SSPS) version 18.0.

\section{RESULTS}

It was found that buccal crestal bone level in one piece group was significantly decreased than two piece group at 3,6 and 9 months. Data are presented in Table (1). (Fig. 1,2,3 and 4). At 3,6 and 9 months; there was non-statistically significant change in mean Bone density between the one piece and two piece implants. Data are presented in Table (2).

It was also found that the peri-implant PD was decreased significantly in one piece group compared to two piece group. Data are presented in Table (3).
TABLE (1) Comparison of crestal bone level in both groups at each observation time (independent t test)

\begin{tabular}{|c|c|c|c|}
\hline \multirow{6}{*}{3 month } & \multirow{2}{*}{ One piece } & Mean & -3.30 \\
\hline & & SD & 1.82 \\
\hline & \multirow{2}{*}{ Two pieces } & Mean & -1.30 \\
\hline & & SD & 0.64 \\
\hline & \multicolumn{2}{|l|}{$\mathrm{t}$} & 3.278 \\
\hline & \multicolumn{2}{|l|}{$\mathbf{P}$} & $0.0042 *$ \\
\hline \multirow{6}{*}{6 month } & \multirow{2}{*}{ One piece } & Mean & -4.66 \\
\hline & & SD & 1.96 \\
\hline & \multirow{2}{*}{ Two pieces } & Mean & -1.30 \\
\hline & & SD & 0.84 \\
\hline & \multicolumn{2}{|l|}{$\mathrm{t}$} & 4.98 \\
\hline & \multicolumn{2}{|l|}{$\mathbf{P}$} & $0.00 *$ \\
\hline \multirow{6}{*}{9 month } & \multirow{2}{*}{ One piece } & Mean & -4.71 \\
\hline & & SD & 1.99 \\
\hline & \multirow{2}{*}{ Two pieces } & Mean & -1.10 \\
\hline & & SD & 0.56 \\
\hline & \multicolumn{2}{|l|}{$t$} & 5.522 \\
\hline & \multicolumn{2}{|l|}{$\mathbf{P}$} & $0.00^{*}$ \\
\hline
\end{tabular}

Significance level $p \leq 0.05$, *significant, $n s=$ non-significant

TABLE (2) Comparison of bone density in both groups (independent $t$ test) and effect of time within the same group (ANOVA test)

\begin{tabular}{|c|c|c|c|c|c|}
\hline \multirow{2}{*}{ Group } & & 3 months & 6 months & 9 months & $\begin{array}{c}\text { P (within } \\
\text { the same } \\
\text { group) }\end{array}$ \\
\hline \multirow{2}{*}{$\begin{array}{c}\text { One } \\
\text { piece }\end{array}$} & Mean & 787.50 & 825.00 & 912.5 & \multirow{2}{*}{$0.387 \mathrm{~ns}$} \\
\cline { 2 - 5 } $\begin{array}{c}\text { Two } \\
\text { pieces }\end{array}$ & Mean & 700 & 675 & 800 & \multirow{2}{*}{$0.072 \mathrm{~ns}$} \\
\cline { 2 - 5 } & SD & 135.1 & 106.07 & 125.1 & \\
\hline \multicolumn{2}{|c|}{$\mathrm{T}$} & 1.403 & 1.690 & 1.546 & \\
\cline { 1 - 4 } $\begin{array}{r}\text { P (between } \\
\text { groups) }\end{array}$ & $\mathbf{0 . 1 7 8 n s}$ & $\mathbf{0 . 1 0 8 n s}$ & $\mathbf{0 . 1 4} \mathbf{n s}$ & \\
\hline
\end{tabular}

-Significance level $p \leq 0.05, *$ significant, $n s=$ non-significant 
TABLE (3) Comparison of probing depth in both groups (independent $t$ test) and effect of time within the same group (ANOVA test)

\begin{tabular}{|c|c|c|c|c|c|}
\hline Group & & $\mathrm{T} 1$ & $\mathrm{~T} 2$ & $\mathrm{~T} 3$ & $\begin{array}{l}\mathrm{P} \text { (within the same } \\
\text { group) }\end{array}$ \\
\hline \multirow{2}{*}{ One piece } & Mean & 2.63 & 3.75 & 3.75 & \multirow{2}{*}{$0.271 \mathrm{~ns}$} \\
\hline & SD & 1.80 & 1.72 & 1.72 & \\
\hline \multirow[b]{2}{*}{ Two pieces } & Mean & 1.25 & 1.50 & 1.50 & \multirow{2}{*}{$0.582 n s$} \\
\hline & SD & 0.35 & 0.71 & 0.71 & \\
\hline \multicolumn{2}{|c|}{$\mathrm{t}$} & 2.379 & 3.831 & 3.831 & \\
\hline \multicolumn{2}{|c|}{ P (between groups) } & $0.029 *$ & $0.0012 *$ & $0.0012 *$ & \\
\hline
\end{tabular}

-Significance level $p \leq 0.05, *$ significant, $n s=$ non-significant

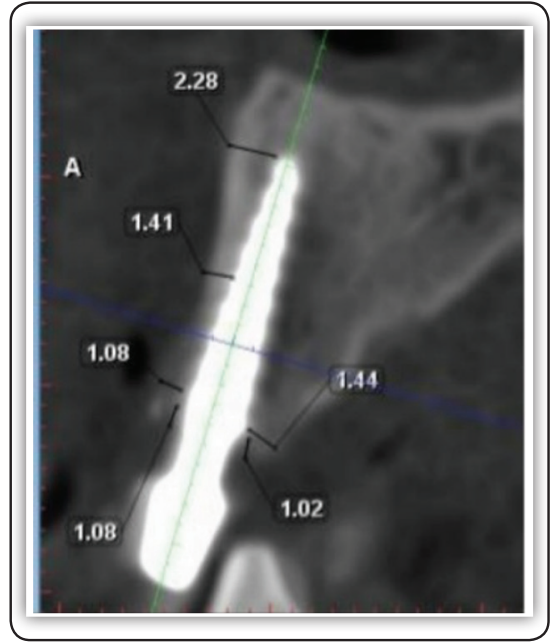

FIG (1) A postoperative CBCT cross section showing sagittal view at the baseline of a one piece implant case

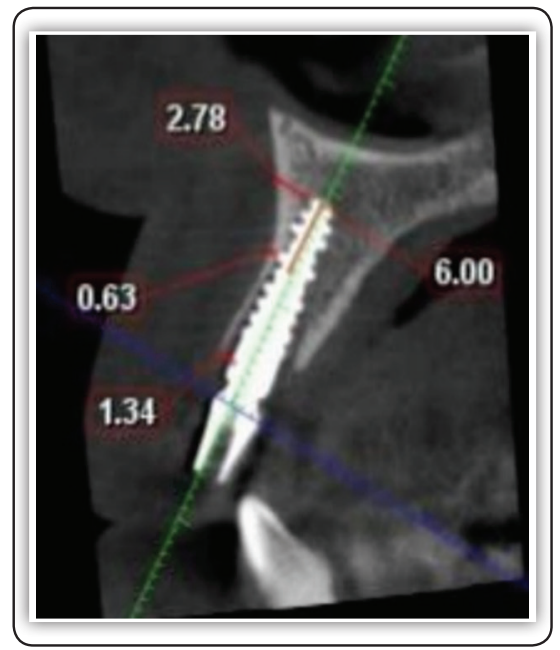

FIG (3) A postoperative CBCT cross section showing sagittal view at the baseline of a two piece implant case.

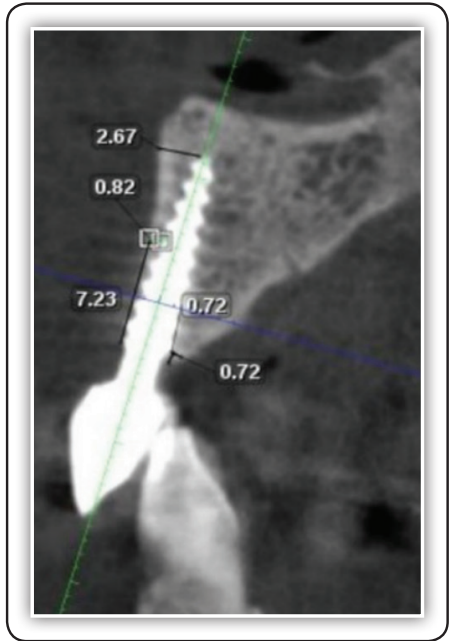

FIG (2) A postoperative CBCT cross section showing sagittal view at 9 months; note the marginal bone level difference after using Superimposition.

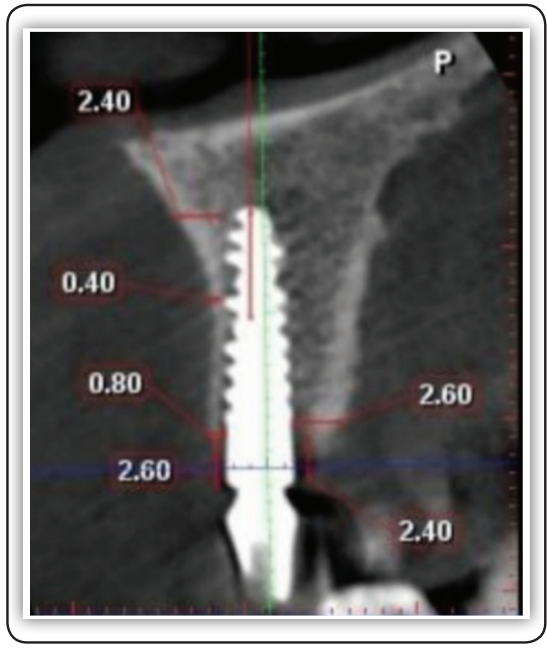

FIG (4) A postoperative CBCT cross section showing sagittal view at 9 months; note the marginal bone level difference. 


\section{DISCUSSION}

Many methods have been used to preserve crestal bone as the use of one piece implant. One-piece implants were introduced to incorporate the transmucosal abutment as an integral part of the implant and thus eliminate the structural weakness built in two-piece implants. The seamless transition of implant to abutment is the design advantage offered by one-piece implants, which mimic the natural tooth in its construction and offer many advantages like strong unibody design, no split parts, single-stage surgery with either flap or flapless approach, and simple restorative techniques. A one-piece implant is intended for immediate function as well as for immediate placement in fresh extraction sockets ${ }^{(5)}$.

The full success of implant-prosthetic treatment is guaranteed by the application of the principles of long-term stability of the bone and healthy soft tissues. The choice of the implant system should be based on the consideration of the following factors: absence of micro-movements, tight implantabutment connection so that bacteria do not migrate into implants), platform-switching (the diameter of an implant is smaller than that of an abutment at the implant-abutment interface), optional placement of an implant below the bone level, micropore surface of an implant and implant neck ${ }^{(9)}$.

The long term preservation of crestal bone height around Osseo-integrated implants is often used as a primary success criterion for different implant systems. The radiographic evaluation of bone forms a very important and viable means of detecting health and stability of bone around the peri-implant hard tissue. A decrease of MBL indicates that the implant is loosening its bony anchorage ${ }^{(7)}$.

The technique of immediate loading was designed because of reduced surgical trauma, improved healing, reduced time of treatment as well as conservation of bone and soft tissues and enhancement of esthetics; these is an agreement with Singh and his colleagues ${ }^{(10)}$.
All the selected cases of the present study have a single-rooted extraction site, the multi-rooted teeth were excluded from the present study, these is in accordance with Atieh et al. (2010) ${ }^{(11)}$, They postulated that outcome of immediate implant in multi-rooted teeth doesn't give a good result since its difficult to attain a good primary stability.

No implant failure among all cases during the present study except 2 cases (two piece implants). One of them was an early failure after one week due to early occlusal eccentric loads. The other was after 2 months and we attributed it to bad oral hygiene patient. According to Misch ${ }^{(12)}$, the factors contributing to early implant failure includes: poor bone quality and quantity, bad general health condition, clinical sign of infection as well as swelling, pus or fistula and lack of primary stability, excessive loading.

With reference to the extracted site selected preoperatively the present work was performed according to Type 1 proposed by Elian and Tarnow classification ${ }^{(13)}$. Since Type 1 extraction site is ideal for immediate implantation because of the presence of intact buccal bone and soft tissue.

In the present study, CBL buccally in one piece implants after 3 month was $3.30 \pm 1.82 \mathrm{~mm}$ and after 6 month was $4.66 \pm 1.96 \mathrm{~mm}$ and after 9 month was $4.7 \pm 1.99 \mathrm{~mm}$. While crestal bone loss buccally in two piece implants after 3 month and 6 month was $1.3 \pm 0.64$ and after 9 month was $1.1 \pm 0.56$. This results showed a significantly greater decrease in the buccal crestal bone in the one piece group. No significant difference concerning the palatal or distal or mesial surface. These findings are in accordance with Ostman et al ${ }^{(14)}$ and Nowzari et al ${ }^{(15)}$.

Several studies ${ }^{(16-19)}$ performed on one piece implant showed high success rate of this technique but those studies were carried out in the mandible. Since; the mandibular bone is more dense with less resorption rate as compared to the maxilla in which the present investigation was conducted in most 
of the cases. So the two piece implant in present clinical trial appeared better as compared to one piece implants.

Moreover; most the studies that used one piece implants were done on fully edentulous patients rather than single tooth replacement ${ }^{(20)(21)}$. So the results of these studies recorded less marginal bone loss due to load distribution.

According to study conducted by Misch ${ }^{(22)}$; the implant quality scale of the present investigation showed $100 \%$ of the two piece implants which considered to be successful ( scale 1), While only $50 \%$ of the cases received one piece implants were recorded as scale 1 , While the remainder of cases showed $25 \%$ scale 2 and $25 \%$ scale 3 .

\section{CONCLUSION}

Within the limits of the present study; immediate loading of two piece dental implants appeared significantly superior than one piece type.

\section{REFERENCES}

1. Schropp L, Wenzel A, Kostopoulos L. Bone healing and soft tissue contour changes following single-tooth extraction: a clinical and radiographic 12-month prospective study. Int J Perio Restor. Dent 2003; 23(4) :313-23.

2. Abrams H, Kopczyk R, Kaplan A. Incidence of anterior ridge deformities in partially edentulous patients. J Prosthet Dent 1987; 57(2):191-4.

3. Nkenke E, Fenner M. Indications for immediate loading of implants and implant success. Clin. Oral Imp. Res. 2006; 17(2): 19-34.

4. Jokstad A. Osseo integration of dental implants. First edition. USA: Wiley-Blackwell; 2008. Chapter 14: Loading protocols and Bioligical ressponce; pp.239.

5. Swart LC, van Niekerk DJ. Simplifying the implant treatment for an unrestorable premolar with a one-piece implant: a clinical report. J Prosthet Dent. 2008;100(2): 81- 5.

6. Prithviraj DR, Gupta V, Muley N, Sandhu P. One- Piece Implants: Placement Timing, Surgical Technique, Loading Protocol, and Marginal Bone Loss. J. Prosthodont . 2013; 22(3): 237-44.
7. Broggini N, McManus L, Hermann J , Medina R, Oates $\mathrm{T}$, Schenk R et al. Persistent acute inflammation at the implant-abutment interface. J Dent Res. 2003;82(3): 232-7.

8. Nandal S, Ghalaut P, Shekhawat H. A radiological evaluation of marginal bone around dental implants: An in-vivo study. Natl J Maxillofac Surg. 2014;5(2): 126-37.

9. French D, Grandin HM, Ofec R. Retrospective cohort study of 4,591 dental implants: Analysis of risk indicators for bone loss and prevalence of peri-implant mucositis and peri-implantitis. J Periodontol. 2019;90(7):691-700.

10. Sazpak P, Szymanska J . The relationship between marginal bone loss around dental implants and the specific characteristics of implant-prosthetic treatment. Curr. Issues Pharm. Med. Sci. 2018; 31(2): 97-100.

11. Singh M, Kumar L, Anwar M, Chand P. Immediate dental placement with immediate loading following extraction of natural teeth. Natl J Maxillofac Surg. 2015; 6(2): 252-5.

12. Atieh M, Payne A, Duncan W, de Silva RK, Cullinan MP . Immediate placement or immediate restoration/loading of single implants for molar tooth replacement: a systemic review and meta-analysis. Int J. Oral Maxillofac impl. 2010; 25(2): 401-15.

13. Misch CE. Nonfunctional immediate teeth in partially edentulous patients. A 10 pilot study of 10 consecutive cases using the maestro dental implant system. Compendium. 1998; 19(1):25-36

14. Elian N, Cho SC, Froum S, Smith RB, Tarnow DP. A simplified socket classification and repair technique. Pract Proced Aesthet Dent. 2007;19(2):99-106.

15. Ostman PO, Hellman M, Albrektsson T, Sennerby L. Direct loading of Nobel Direct and Nobel Perfect one-piece implants: a 1-year prospective clinical and radiographic study. Clin Oral Implants Res. 2007;18(4):409-18.

16. Nowzari H, Chee W, Yi K, Pak M, Chung WH, Rich S et al. Scalloped dental implants: a retrospective analysis of radiographic and clinical outcomes of 17 NobelPerfect implants in 6 patients. Clin Implant Dent Relat Res. 2006;8(1):1- 10 .

17. Balshi TJ, Wolfinger GJ. Immediate loading of Brånemark implants in edentulous mandibles: a preliminary report. Implant Dent. 1997;6(2):83- 8.

18. Randow K, Ericsson I, Nilner K, Petersson A, Glantz PO. Immediate functional loading of Brånemark dental implants. An 18-month clinical follow-up study. Clin Oral Implants Res. 1999;10(1):8- 15. 
19. Schnitman PA, Wohrle PS, Rubenstein JE. Immediate fixed interim prostheses supported by two-stage threaded implants: methodology and results. J Oral Implantol. 1990;16(2):96-105.

20. Tarnow DP, Emtiaz S, Classi A. Immediate loading of threaded implants at stage 1 surgery in edentulous arches: ten consecutive case reports with 1- to 5-year data. Int J Oral Maxillofac Implants. 1997;12(3):319- 324.

21. De Bruyn H, Raes S, Ostman PO, Cosyn J. Immediate loading in partially and completely edentulous jaws: a re- view of the literature with clinical guidelines. Periodontol 2000. 2014;66(1):153- 187.

22. Shigehara S, Ohba S, Nakashima K, Takanashi Y, Asahina I. Immediate Loading of Dental Implants Inserted in Edentulous Maxillas and Mandibles: 5-Year Results of a Clinical Study. J Oral Implantol. 2015;41(6):701-5.

23. Misch CE. The implant quality scale: a clinical assessment of the health--disease continuum. Oral Health. 1998;88(7):15-26. 